\title{
A Preliminary Study on the Characteristics of Plateau Training for Canoe
}

\author{
Yabin He ${ }^{1, \text { a }}$, Shuai Liu ${ }^{2, b}$, Guoqin Jiang ${ }^{1, ~ c, ~ * ~}$ \\ ${ }^{1}$ School of Physical Education, Jianghan University, Wuhan 430056, China \\ ${ }^{2}$ Wuhan Sport University, Wuhan 430056, China \\ a469954909@qq.com, b46133963@qq.com, '¹17748899@qq.com \\ *Author for correspondence: 117748899@qq.com
}

Keywords: Canoe, Plateau training, Feature

\begin{abstract}
Canoeing is an aerobic, anaerobic hybrid project in the training and competition on the human body aerobic capacity and oxygen lactic acid capacity requirements are high. Recognizing the concept of plain education in plateau training and improving athletes' aerobic ability, strength endurance and special skills, laying a solid foundation for the development and improvement of comprehensive athletic ability during the competition period. Altitude training refers to the purposeful and systematic organization of athletes in areas with suitable altitude and carrying out regular special sports training methods. This study can make more people understand the congenital physiological conditions of high altitude, mainly in; cardio-pulmonary function, tall, well adapted to aerobic items - water aerobics project. For the future national team aerobic project selection to provide a theoretical basis. Secondly, the time of plateau training is different from the time and intensity of general plain training. This study can make more coaches and athletes understand the difference between plateau training and plain training in order to arrange training more scientifically in later training Time and training content.
\end{abstract}

\section{Introduction}

Canoeing is aerobic endurance project, in the process of training and competition to human aerobic energy supplying capacity and anaerobic lactic acid capacity requirements are very high. Gansu province canoeing team canoe project group coaches and athletes has been in Plateau training of experience. Plateau training purpose is inherited, and consolidate and carry forward plateau training of results, exploration efficient multiple competitive ability factors of system training and comprehensive arrangements, practice line plateau training plain of concept, improve athletes of has oxygen ability, and forces endurance and special skills, for competition period comprehensive competitive ability of development and improve lay solid of Foundation. Altitude training refers to the purposeful, planned to organize players into areas with appropriate altitude, methods for special training on a regular basis. Training workers at home and abroad in the 1960 of the 20th century and have noted that the athletes living in the plateau region has high durability. Altitude training is the widespread attention at home and abroad the sports sector. Higher altitude in Gansu province, long plateau of athletes in terms of physical function has a greater advantage than plain people. This article from canoeists in Gansu province and other aspects of physical fitness, skill and psychological quality of the research and analysis, found women Canoeers strength quality in Gansu province features strong performance for endurance, body strength characteristics of excellent; male Canoe athletes for endurance and performance characteristics of trunk strength superior; performance for endurance and strength characteristics of rowing torso strength superior features than excellent.

Plateau training is essentially a means to improve the performance of athletes by raising the plateau as a kind of sports resource. It is a kind of load training method that integrates oxygen load, exercise intensity load and psychological load. Plateau training began about 50 years in the 20th century, half a century of history. Plateau training was carried out in our country in the 1960s, which 
is also earlier in the international sports arena. With the continuous development of competitive sports and the improvement of sports techniques, altitude training as a powerful training method of Canoeing projects at home and abroad has attracted more attention and in-depth research in recent Olympic Games. At Athens Olympic Games and Beijing Olympic Games, Meng Guanliang and Yang Wenjun won the first medal of the Athens Olympic Games for Canoeing in China and the Olympic Games in Beijing relied largely on the results of plateau training.

People living in the plateau, hematopoietic erythrocytes and hemoglobin increased with the nervous system, body fluid regulation, home and long-standing population in the plateau, the body due to long-term hypoxia stimulation, making increased erythropoietin, increased red blood cells, hemoglobin Increased volume and hematocrit. Besides the increase of erythrocyte count, the properties of erythrocytes also changed. The reticulocyte maturation and the life span of erythrocytes were shortened. The hemoglobin in each erythrocyte was slightly increased, the erythrocyte fragility test was reduced, the electrophoresis ability was enhanced, and the content of phosphoglyceride in erythrocytes was increased.

The effective implementation of altitude training depends on the accumulation of regular knowledge and experience of altitude training. The human body in the plateau hypobaric hypoxia environment training, the use of plateau hypoxia and exercise of dual stimulation, making the athlete's body have a strong emergency response, in order to achieve increased levels of exercise [2]. The effect of plateau training is affected by the combination of athletes' training level, exercise load stimulation, training time and training methods and other factors. There is no uniform fixed pattern in plateau training. Compared with plain training, altitude training can not only better tap the potential of the human body and improve the training level, but also has a higher risk, that is desirable and difficult to grasp one hand. This is the charm of altitude training. It is not easy to train well in high altitude. Because in the process of carrying out plateau training, the athletes will be subject to many factors from both positive and negative aspects of the incentive and constraints, unremitting exploration of the law of plateau training, eliminate pros and cons, improve the scientific level of plateau training and its success rate is Sports research workers one of the key areas of research. In recent years, the research on altitude training has aroused great attention and participation of the coaches and sports scientific research. However, most of the research reports focus on track and field, cycling and other projects. However, there are few reports on Canoe plateau training, especially in the theoretical research. There have been many gaps in this area of research, with very little information and very systematic information. This topic intends to study the theory and practice of Canoe plateau training to explore the influence of Canoe plateau training on altitude selection, intensity selection, training time, nutrition recovery and physiological and biochemical indicators. In the future, Gansu made good achievements in the next plateau competition, ensured the effective implementation of plateau training, reduced risks and increased the success rate.

\section{Method}

\subsection{Documentation Method}

Through the Chinese Journal Net, National Library and Wuhan Institute of Physical Education Library, collected a large number of documents on plateau training theory and other aspects of a large number of documents, the system access to 1990 - 2004 - "sports history", "Sports Journal", "Beijing Journal of Sports University, Journal of Wuhan Institute of Physical Education, Shanghai Institute of Physical Education, Guangzhou Sport University Newspaper and other sports journals in more than a dozen countries and information on plateau training. Basically mastering the development of plateau training in our country. The collection of these data has given me a general idea of the status quo of plateau training research. This study found a suitable entry point. On the basis of extensive reading and sorting of all kinds of documents, according to the characteristics of Canoeing items, the relevant materials are mainly read and analyzed, and classified and integrated. 


\subsection{Expert Interview Method}

On the basis of the theoretical research, this paper draws up an outline of the interview, and separately discusses the current situation and existing problems of plateau training in our country, as well as the value and practical significance of plateau training theory research and how to further expand its research fields and other related issues. The front-line leaders, coaches, researchers, athletes, experts in plateau training, human sports science and sports training experts who have been on plateau training for many times use the form of one-on-one interviews and interviews.

\subsection{Statistical Analysis}

Statistical analysis refers to the research object by the scale, speed, scope, extent and other quantitative relationship analysis, understanding and revealing the interrelationships between things, changes and trends in order to achieve the correct interpretation of things and predict a Research methods. In this paper, Excel and SPSS11.5 software are used to carry out statistics on the training of sports and biology during winter training and pre-competition training of a provincial canoeing team to provide data support for the dissertation writing and to ensure the scientific Sex and rigor.

\section{Results}

Physical fitness in the field of sports training covers the following aspects: body shape, strength quality, endurance quality, speed quality, flexible quality and coordination. Body shape mainly refers to the external and internal body structure, body shape of Canoeer main form is reflected in: height, weight, upper arm length, upper arm tension Wai, upper arm relaxation Wai, chest circumference, finger spacing, stretching arm length, sitting Arm length, kneeling arm length, shoulder width, subscapular skinfold thickness arm skinfold thickness.

Table 1 Basic body shape of canoe athletes

\begin{tabular}{ccccc}
\hline Sex & Age(Year) & $\begin{array}{c}\text { Average } \\
\text { training(Year) }\end{array}$ & Weight(kg) & Height(cm) \\
\hline Male & 20.94 & 6.39 & 82.47 & 186.21 \\
Female & 20.87 & 6.21 & 67.46 & 174.25 \\
\hline
\end{tabular}

Table 1 shows that the average height of canoeists is $185.20 \mathrm{~cm}$, with a greater proportion of between $184 \mathrm{~cm}$ and $188 \mathrm{~cm}$, accounting for 61.7\%; the average body weight is $82.95 \mathrm{~kg}$, mostly concentrated in 80 to $85 \mathrm{~kg}$, accounting for about 55.8\%; the average age 21.10 years old, more concentrated in two age groups, 19-21 years old, accounting for about 38.2\%, 26-28 years old athletes accounted for about $17.6 \%$.

Male Canoe athletes average height of $186.21 \mathrm{~cm}$, mostly concentrated in $185 \mathrm{~cm}$ to $189 \mathrm{~cm}$, accounting for $50.71 \%$; average weight of $82.47 \mathrm{~kg}$, concentrated in 81 to $86 \mathrm{~kg}$ more, accounting for $57.74 \%$; average age of 20.94 years of age, and more concentrated in 19-24 years old, accounting for $60.56 \%$. Female Canoe athletes average height of about $174.25 \mathrm{~cm}$, mostly concentrated between $172 \mathrm{~cm}$ to $175 \mathrm{~cm}$, accounting for $64.28 \%$; average weight of $67.46 \mathrm{~kg}$, mostly concentrated in 65 to 70 $\mathrm{kg}$, accounting for about $59.52 \%$; The average age is 20.87 years old, more concentrated 18 to 21 years, accounting for $64.29 \%$.

In the world of canoeing, the body shape of canoeists has basically stabilized. Compared with the foreign athletes of the 2008 Olympic Games, athletes of Gansu province have lighter weight than male athletes, while rowing boats and women's skins are slightly heavier. However, On possession of advantages, indicating that the canoe project in Gansu province athletes already have a good form of indicators. Grasping the regularity of body structure of Canoe is conducive to the selection of early training work, which is conducive to ensuring the connection between the cultivation of outstanding athletes and the outstanding talents in Gansu Province and laying a good foundation for the 
improvement of sports performance. Raise our Canoe level.

Table 22008 Olympic Games foreign canoe athletes basic form

\begin{tabular}{rccc}
\hline Sex & Age(Year) & Weight $(\mathrm{kg})$ & Height $(\mathrm{cm})$ \\
\hline Male & 25.9 & 86.4 & 185.2 \\
Female & 25.9 & 66.3 & 172.6 \\
\hline
\end{tabular}

\section{Discussion and Conclusion}

Canoe athletes common physical characteristics; arm length, developed upper limbs, stout body. Canoe athletes with high body composition requirements, manifested as low body fat content; and rowing project on the athlete's overall sturdiness requirements higher, the performance of athletes with a thicker bust specifically, our province canoeists The body is characterized by; cardiopulmonary function and male hormone levels. Quality characteristics of our province canoe athletes; strong trunk strength, special endurance and anaerobic ability. The technical characteristics of our province canoe athletes are; have strong pull pulp strength. The psychological characteristics of our province canoe athletes are: have a good ability of self-confidence and attention, ability to overcome patience and restrain irrelevant. The structure model of competitive ability of canoe athletes in our province is based on a mathematical description and theoretical induction of its athletic system by screening the indicators that reflect the athletic ability of canoe athletes. The purpose is to make excellent canoeing in our province Athlete's athletic ability system to maximize the optimization. This will reveal the structural characteristics of the athletic ability of the project in depth, provide guidance for scientific material selection, and serve for many years planning and monitoring of the training process.

\section{References}

[1] SC Forbes, MD Kennedy, NB Boule, G Bell Determination of the optimal load setting for arm crank anaerobic testing in men and women. Intelational Journal of Sports Medicine, Vol. 35 (2014), No. 10, p. 835-839.

[2] M Sheykhlouvand, SC Forbes, Aerobic capacities, anaerobic power, and anthropometric characteristics of elite female canoe polo players based on playing position. Sport Sciences for Health, Vol. 1 (2017), p.1-6.

[3] S Anna, S Valery, Aerobic and Anaerobic Capacities of Different Age and Performance Female Fencers. Medsportpress, Vol. 12 (2006) No.2, p.214-217.

[4] Forbes SC, Kennedy MD, Bell GJ (2013) Time-motion analysis, heart rate, and physiological characteristics of international canoe polo athletes. Journal of Strength \& Conditioning Research, Vol. 27(2013) No. 20, p. 2816-2822.

[5] Emilio J. Martínez-López, Alberto Grao-Cruces, José E. Moral-García, et al. Intervention for Spanish Overweight Teenagers in Physical Education Lessons. Journal of Sports Science \& Medicine. Vol. 11(2012) No. 2, p. 312-321.

[6] Nicola A. Maffiuletti, Physiological and methodological considerations for the use of neuromuscular electrical stimulation. European Journal of Applied Physiology. Vol. 110(2010) No. 2, p. 223-234

[7] AF Ugras, Effect of high intensity interval training on elite athletes' antioxidant status. Science \& Sports, Vol. 28 (2013) No.5, p.253-259.

[8] JX Li, RCH So, YW Yuan, Muscle strain and cardiovascular stress in fencing competition [C]. 
Proceeding of the 5th IOC World Congress on Sports Sciences (Sydney, 31 Oct.-5 Nov. 1999). Vol. 5, p.222.

[9] Barber-Westin, Sue D; Hermeto, Alex A; Noyes, Frank R, et al. A Six-Week Neuromuscular Training Program for Competitive Junior Tennis Players. Journal of Strength \& Conditioning Research. Vol. 24(2010) No. 9, p. 2372-2382. 